\title{
A associação de empresas no Brasil em arranjos produtivos locais (APL) como fator de obtenção de vantagem competitiva
}

Daniel Portillo Serrano ${ }^{1}$

\section{Resumo}

Nos últimos anos, diversos estudos foram publicados sobre a importância da associação ou aglomeração de empresas em arranjos produtivos como forma de desenvolvimento, principalmente, em prol das capacidades produtivas e da Vantagem Competitiva. Diversos estudos têm sido publicados recentemente, confirmando a viabilidade econômica desses arranjos. As pesquisas têm mostrado que, através da cooperação, são criados diferenciais competitivos para as firmas estabelecidas nesses arranjos que as diferenciam das demais. As aglomerações configuradas dessa forma são, normalmente, chamadas pelos diversos autores de Arranjos Produtivos Locais, ou APLs. Diversos outros nomes, no entanto, têm aparecido na literatura como: Sistemas Locais de Inovação, Sistemas Locais de Produção, Sistemas Produtivos Locais e Clusters. O Governo brasileiro, entretanto, denomina oficialmente esse tipo de aglomeração como Arranjos Produtivos Locais, passando, portanto, a ser a denominação que utilizaremos neste trabalho. O objetivo deste texto é mostrar que as empresas unidas em arranjos produtivos possuem fatores de vantagens competitivas não disponíveis, quando atuam isoladamente, utilizando os modelos de Porter e Mytelka e Farinelli.

Palavras-chave: Arranjos Produtivos Locais. Vantagem Competitiva. Redes. Empresas em Rede. Clusters. Aglomerações de empresas. Sistemas Locais de Produção.

1 Daniel Portillo Serrano é graduado em Comunicação Social Pela Anhembi Morumbi e pós graduado em Administração pela Unibero. Mestrando em Administração de Empresas pela UNIP 


\section{Introdução}

Os arranjos de empresas em sistemas locais de produção podem ter diferentes nomes. (SUZIGAN et al., 2003). Para Suzigan et al (2003), há diversos fatores que têm variado as caracterizações e, consequentemente, os nomes e denominações dos arranjos, entre eles a:

[...] história, evolução, organização institucional, contextos sociais e culturais nos quais se inserem, estrutura produtiva, organização industrial, formas de governança, logística, associativismo, cooperação entre agentes, formas de aprendizado e grau de disseminação do conhecimento especializado local (SUZIGAN et al., 2003).

Duas denominações, no entanto, têm sido encontradas em profusão, na literatura existente, ARRANJOS PRODUTIVOS LOCAIS, ou APLs e SISTEMAS PRODUTIVOS LOCAIS, ou SPLs. Órgãos oficiais governamentais, como o BNDES e o Ministério do Desenvolvimento, Indústria e Comércio Exterior (MDIC), responsáveis pelo fomento e desenvolvimento desse tipo de arranjo, utilizam a primeira denominação (APL), enquanto algumas instituições acadêmicas têm optado por utilizar SPL. Esse é o caso da Rede de Pesquisa em Sistemas Produtivos e Inovativos Locais - Redesist - que é coordenada pela Universidade Federal do Rio de Janeiro, através do Instituto de Economia. Para o presente trabalho, optamos por APL, e essa será a denominação adotada no desenvolvimento do texto.

Para o MDIC (2004), APLs são:

Aglomerados de agentes econômicos, políticos e sociais, com atividades correlatas ou afins, localizados em um mesmo território, que apresentam vínculos consistentes de articulação, interação, cooperação e aprendizagem entre si e com outros atores locais tais como governo, associações empresariais, instituições de crédito, ensino e pesquisa (MDIC, 2004).

O conjunto de ações efetuadas por um grupo de empresas oferece a chamada eficiência coletiva, que passa a ser o principal fator de determinação das vantagens competitivas de empresas locais (SCHMITZ; NADVI, 1999). 
Os APLs podem comportar diversos tamanhos de empresa, seja pelo seu porte, pelo seu faturamento ou por sua área física ocupada. Não há uma determinação de tamanho mínimo ou máximo para que as empresas se agrupem em arranjos locais. Um dos fatores proeminentes, no entanto, é o fato de as empresas não estarem integradas verticalmente, mas horizontalmente, já que um dos objetivos que resultarão em vantagens competitivas será a atração de outras empresas, sejam elas de logística, fornecedoras ou de apoio (SUZIGAN et al., 2003).

Já para Roxo (2007, p. 01):

A estrutura de um setor influencia e determina as "regras do jogo concorrencial" de uma forma fundamental, bem como delimita as estratégias potenciais que a empresa pode vir a adotar e implementar. A intensidade concorrencial num setor não é um fator do acaso. A concorrência numa indústria baseia-se na respectiva estrutura econômica e ultrapassa o comportamento das empresas que nela operam.

Dessa forma, o arranjo local aparenta ser uma forma de se obter os fatores necessários para a obtenção da vantagem competitiva.

\section{Objetivos e metodologia}

O objetivo deste trabalho é verificar se as empresas associadas em Arranjos Produtivos Locais realmente apresentam vantagens competitivas em relação às empresas que trabalham isoladamente. Alguns modelos teóricos como, por exemplo, "As cinco forças de Porter," serão analisados e terão sua teoria confrontada entre empresas que atuam de forma isolada e empresas integrantes de Arranjos Produtivos Locais, menos propensas a guerras de mercado. Para a comparação, serão utilizadas as 5 forças de Porter aplicadas a empresas inovadoras associadas em APLs, conforme o modelo e tipologia de APLs de Mytelka e Farinelli. 


\section{A força das organizações dos APLs}

As empresas organizadas em APLs apresentam, entre outros, graus e níveis de competição, cooperação e tecnologia superiores a empresas que atuam isoladamente; a intensidade de cada um desses níveis pode ser diferenciada de acordo com o tipo de organização do APL (SANTOS; DINIZ; BARBOSA, 2004).

Uma das tipologias mais utilizadas em estudos sobre APLs é a apresentada por Mytelka e Farinelli em 2000. As autoras mostram uma tabela com 3 níveis de intensidade de ligação das empresas integrantes de APLs e oferecem forças ou fraquezas em determinados fatores dentro do APL, como níveis de tecnologia, tamanho das empresas, cooperação e competição.

Assim, um APL formado informalmente não terá, por exemplo, capacidade de gerar em conjunto novos produtos, enquanto um APL organizado oferecerá algum nível de lançamentos. Já em Clusters inovadores, os novos produtos serão desenvolvidos continuamente (MYTELKA; FARINELLI, 2000).

A Figura 1 - mostra os níveis de competitividade das empresas, conforme o grau de organização.

\begin{tabular}{|c|c|c|c|}
\hline & $\begin{array}{c}\text { APLs } \\
\text { informais }\end{array}$ & $\begin{array}{c}\text { APLs } \\
\text { organizados }\end{array}$ & $\begin{array}{c}\text { APLs } \\
\text { inovadores }\end{array}$ \\
\hline $\begin{array}{c}\text { Tamanho das } \\
\text { empresas }\end{array}$ & $\begin{array}{c}\text { Micro, pequenas e } \\
\text { médias }\end{array}$ & $\begin{array}{c}\text { Pequenas e } \\
\text { médias }\end{array}$ & $\begin{array}{c}\text { Pequenas, médias e } \\
\text { grandes }\end{array}$ \\
\hline $\begin{array}{c}\text { Existência } \\
\text { de liderança }\end{array}$ & $\begin{array}{c}\text { Baixo nível de } \\
\text { liderança }\end{array}$ & Baixo a médio & $\begin{array}{c}\text { Alto nível de } \\
\text { liderança }\end{array}$ \\
\hline $\begin{array}{c}\text { Capacidade } \\
\text { inovadora }\end{array}$ & $\begin{array}{c}\text { Pequena capacidade } \\
\text { inovadora }\end{array}$ & Alguma & Contínua \\
\hline $\begin{array}{c}\text { Cooperação } \\
\text { de cooperação e } \\
\text { especialização }\end{array}$ & Alguma a alta & Média a alta \\
\hline Competição & Alta competição & Alta & Alta \\
\hline Exportação & $\begin{array}{c}\text { Pouca ou nenhuma } \\
\text { exportação }\end{array}$ & Média a alta & Alta \\
\hline Confiança & Pequena & Alta & interna
\end{tabular}




\begin{tabular}{|c|c|c|c|}
\hline & $\begin{array}{c}\text { APLs } \\
\text { informais }\end{array}$ & $\begin{array}{c}\text { APLs } \\
\text { organizados }\end{array}$ & $\begin{array}{c}\text { APLs } \\
\text { inovadores }\end{array}$ \\
\hline $\begin{array}{c}\text { Nível de } \\
\text { Tecnologia }\end{array}$ & Pequena & Média & Média \\
\hline $\begin{array}{c}\text { Ligações } \\
\text { entre as } \\
\text { empresas }\end{array}$ & Algum & Algum & Difundido \\
\hline $\begin{array}{c}\text { Novos } \\
\text { Produtos }\end{array}$ & Poucos ou nenhum & Alguns & Continuamente \\
\hline
\end{tabular}

Figura. 1 Tipologia de APLs conforme o grau de organização

Fonte: Mytelka e Farinelli (2000)

Para o presente trabalho, serão consideradas as empresas apontadas pelas autoras como "inovadoras", descritas na terceira coluna da Figura 1, já que não há sentido em analisar vantagens competitivas em associações ou arranjos informais, nos quais o nível de inovação, de novos produtos e de tecnologia, entre outros, seja pequeno ou inexistente.

As arenas competitivas em setores e as cinco forças.

Apesar da dificuldade de se definirem as arenas competitivas em diversos setores, Michael Porter estabeleceu um modelo que integrou a estratégia corporativa e a economia de um determinado setor.

Esse nível de ponderação pode ser importante para a análise de competitividade em APLs, porque exige uma intensidade e profundidade de relacionamento, de maneira geral, superior à que ocorre com os demais públicos relevantes isoladamente. Traz à reflexão a formulação de uma estratégia fundamentada em uma dinâmica da rivalidade competitiva. (TAVARES, 2007).

Em um determinado APL, a intensidade concorrencial de um setor irá depender dessas cinco forças básicas (ROXO, 2007).

Rivalidade entre os concorrentes;

Poder de negociação dos clientes;

Poder de negociação dos fornecedores;

Ameaça de entrada de novos concorrentes; e

Ameaça de produtos substitutos (PORTER, 1997). 
As forças não atuam isoladamente; para Ferreira, Reis e Pereira (2008), “[...] é o conjunto destas forças que determina o potencial de lucro final na indústria”.

A rentabilidade de uma empresa é, segundo Porter, determinada por essas forças, já que elas poderão influenciar os custos, os preços e os investimentos necessários para manter-se em certo setor, além da rentabilidade do próprio setor (TAVARES, 2007).

As cinco forças não atuam de forma idêntica para todas as empresas. Da mesma forma, cada uma poderá variar de setor para setor e de empresa para empresa. A importância de cada uma será resultante da estrutura industrial, razão pela qual, um APL poderá ser um fator preponderante para a obtenção de vantagens competitivas em empresas de um determinado setor.

\section{A rivalidade entre os concorrentes em um APL}

A rivalidade de um setor específico apenas existe devido ao fato de que os concorrentes se sentem pressionados pelos demais ou porque vislumbram uma oportunidade de melhorarem a sua posição naquele determinado setor. Quando uma empresa de um setor efetua uma ação no mercado, origina a retaliação por parte de outra empresa concorrente, já que a posição desta pode estar sendo ameaçada (ROXO, 2007).

Guerras por preços mais baixos e atrativos ao mercado são exemplos dessas manobras. A rentabilidade, no entanto, compromete-se proporcionalmente à intensidade das guerras. A propaganda pode ser outra forma de ação que causa reação. Quando um participante de um setor inicia sua campanha, exigirá que as demais empresas desse setor a acompanhem, sob o risco de verem a sua marca esvanecer na lembrança do público consumidor. O setor ganha divulgando seus produtos, mas cada empresa reduz suas margens com custos crescentes de divulgação. 
A associação em APLs pode ser uma boa resposta a esta barreira, já que:

a) raramente integrantes de um Arranjo Produtivo Local entram em guerras de preços; e

b) as campanhas publicitárias são feitas, na maioria das vezes, de forma cooperada, maximizando os resultados e minimizando os custos.

Outro fator a favor das integrantes de APLS é que,em determinados segmentos, devido ao fato de estarem rodeadas por muitas empresas, algumas organizações iniciam ações de mercado sem serem notadas pelas demais, que percebem as manobras da concorrente, muitas vezes quando já é tarde. Em um APL, raramente uma empresa tomará uma iniciativa que venha a prejudicar as demais empresas do arranjo.

Através do modelo de Porter, fica claro que a diferenciação de produtos entre as diversas empresas evitará uma guerra de mercado. Cada uma produz o seu produto, com o seu diferencial. Dessa forma, não há custos relacionados a guerras de mercado. Isso implica, no entanto, que, para o mercado, cada fabricante deverá estar produzindo um produto diferente, sendo que, cada indústria arcará com seus custos de desenvolvimento, pesquisa, produção, vendas e logística. Empresas em APLs poderão, ao contrário, organizarem-se para produzir os mesmos produtos, com vantagens sobre as empresas isoladas na alocação de custos de cada fase do processo de pesquisa, de desenvolvimento, de produção, de vendas e de distribuição. De acordo com Roxo (2007, p. 3):

Os concorrentes que atuam num setor podem diferir entre si nas estratégias, origens, personalidades e ter objetivos diferentes e modos distintos de concorrer. Dificilmente interpretam as intenções dos outros concorrentes não chegando a acordo quanto à definição das regras de jogo na indústria.

É fácil perceber que, em um APL, a situação seria exatamente inversa à proposta pelo autor. 


\section{0 poder de negociação dos clientes.}

Tendo como base o modelo de Porter, percebe-se que os clientes são fatores de influência dos fabricantes, já que eles poderão ocasionar a diminuição de preços e exigir melhores níveis de qualidade e serviços agregados ou de pós-venda. O consumidor joga um concorrente contra o outro na disputa de sua preferência. Essa manobra provoca a redução de margens, com consequente diminuição de rentabilidade de todo o setor. Normalmente, consumidores são considerados fortes influenciadores se:

a) a rentabilidade do setor é baixa;

b) a qualidade do produto não é fator importante no momento da compra;

c) possuem informações detalhadas sobre os preços e custos dos produtos; $\mathrm{e}$

d) os produtos não oferecem diferencial entre si.

Nesses casos, as empresas, acabam abandonando grupos de clientes fortes, optando vender para quem oferece menor poder de negociação.

Mais uma vez, empresas em APLs mostram-se mais protegidas contra esse tipo de grupos de clientes. Havendo qualidade, preço e serviços de pós-venda semelhantes entre os oferecidos pelas empresas dos arranjos, o poder de negociação dos clientes será substancialmente reduzido, aumentando sobremaneira os fatores de vantagem competitiva para as organizações.

\section{0 poder de negociação dos fornecedores.}

De acordo com Tavares (2007, p. 178), “O poder de negociação dos fornecedores determina até que ponto eles, não as empresas fabricantes, irão apropriar-se de parte do valor criado para compradores e parcelas do retorno sobre o investimento “.

Os fornecedores exercem poder sobre um setor ou segmento de mercado, ameaçando aumentar preços ou reduzir a qualidade de seus produtos ou serviços (ROXO, 2007). 
Um grupo de fornecedores pode ser perigoso para uma empresa se:

a) não tem produtos substitutos;

b) se for mais concentrado que o grupo de empresas que compram esses produtos;

c) se for um grupo concentrado e coeso; e

d) se a indústria compradora for um cliente importante para os fornecedores.

Há como prática considerar-se como fornecedor apenas a indústria que oferece insumos, matéria-prima ou componentes para outra indústria; , entretanto, outro determinante que pode deter poder sobre os diversos segmentos industriais é a sua mão de obra.

Cabe nessa força também uma análise da superioridade das empresas integrantes de APLs sobre as demais. Quando arranjadas em grupo, as indústrias passam a deter o poder sobre os fornecedores, já que podem combinar preços máximos de compra, prazos, selecionar empresas e centralizar as compras. Esse fato não ocorre em empresas não associadas, concorrendo pelo mesmo mercado, setor ou segmento.

\section{Ameaça de entrada de novos concorrentes}

Geralmente, a cada novo entrante, os elementos de retorno sobre o investimento (preço, custos, e investimento) são afetados, trazendo prejuízo para a rentabilidade das empresas (MAY; LEMOS, 1998). Quanto maior o número de empresas entrando em um determinado segmento, maior a probabilidade de queda de preços e rentabilidade dos atuais participantes (PORTER, 1989).

Segundo May e Lemos (1989, p. 3):

A entrada eminente de um concorrente cria expectativas no mercado, refletindo na demanda pelos produtos das empresas atuais. Os clientes potenciais esperam uma redução de preços em médio prazo, havendo uma diminuição no ritmo de transações no mercado. Com o acirramento da concorrência os custos de propaganda/comunicação 
também são intensificados a fim de evitar a migração dos clientes para a concorrente, além da necessidade de realizar investimentos em novas tecnologias.

O modelo das cinco forças recomenda algumas barreiras contra a entrada de novos concorrentes no setor, entre elas, acesso fácil à distribuição e logística, curva de aprendizagem, acesso a insumos necessários para a produção e política governamental favorável (TAVARES, 2007).

\section{Ameaça de produtos substitutos}

Além da concorrência que as empresas enfrentam em seus setores ou segmentos, estão em constante concorrência contra organizações de outros setores. Isso se deve à possibilidade de entrada no mercado de um produto, não concorrente, mas que venha a substituir o atual produto produzido por uma indústria.

Produtos substitutos são aqueles que, apesar de diferentes, desempenham funções semelhantes ou similares ou equivalentes (TAVARES, 2007). Os produtos substitutos acabam, por si só, limitando os preços dos produtos atuais, já que para uma variação substancial no preço, o risco da entrada de um produto substituto pode ser ampliado. O desenvolvimento acaba fornecendo subsídios para novas tecnologias que criarão novos produtos, já que de acordo com Roxo (2007, p. 7):

[...] a identificação de produtos de substituição resulta da pesquisa de outros produtos que podem desempenhar a mesma função. Os produtos substitutos que merecem atenção especial são aqueles cuja relação preço/rendimento tem tendência a ser superior à dos produtos do setor, ou são produzidos em setores altamente rentáveis.

Em muitos casos, os produtos substitutos são produzidos pelo próprio APL, reduzindo o risco de que empresas alheias ao arranjo comprometam o rendimento das empresas associadas. 
Fica claro, portanto, que a análise de uma organização inserida em um APL ganha Vantagem Competitiva sob a luz das cinco forças de Porter, quando comparada a uma empresa isolada, concorrendo no mercado, por si só.

A Figura 2 - mostra os diversos fatores envolvidos nas cinco forças competitivas de uma indústria isolada.

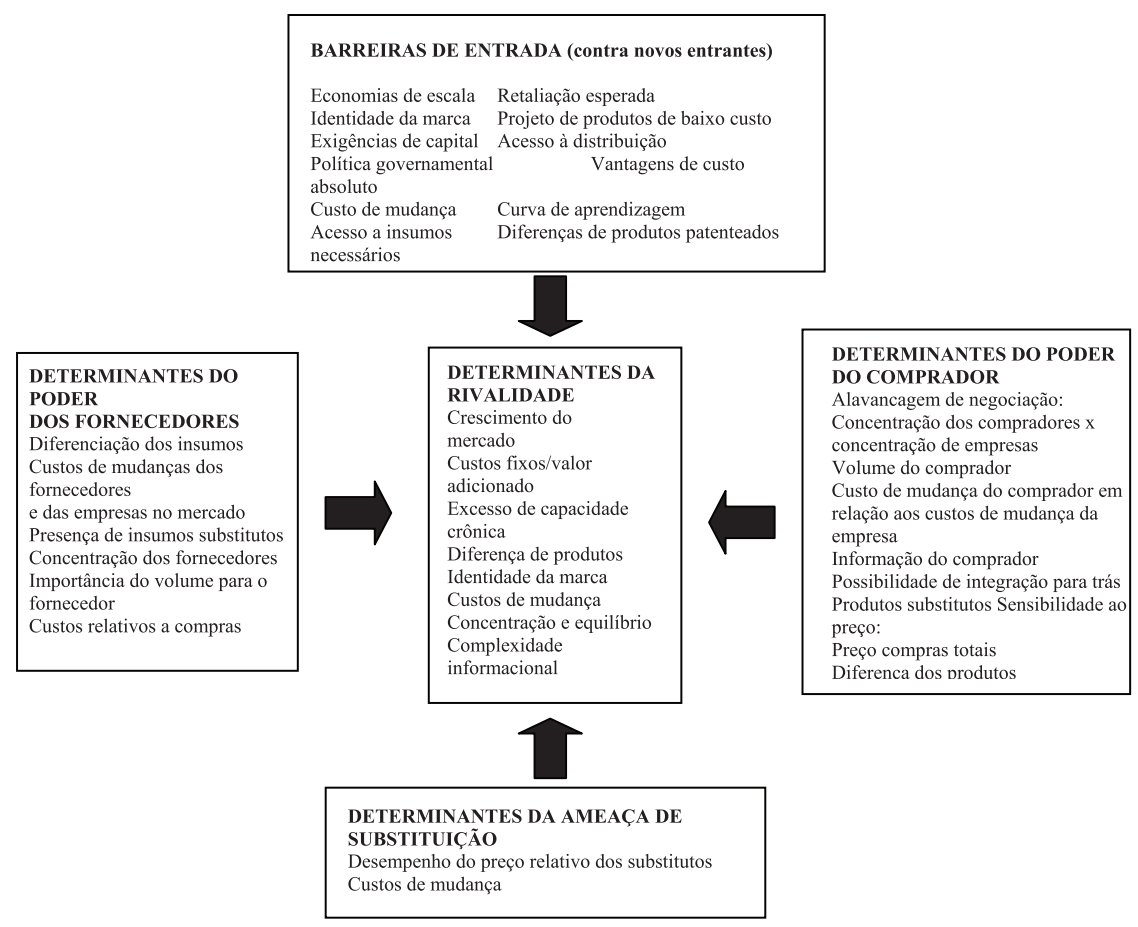

Figura 2 - As cinco forças competitivas de uma indústria.

Fonte: Tavares, 2007.

Sob a perspectiva de associações em APLs, no entanto, as barreiras propostas por Porter adotam outros formatos, já que parte delas é inerente ao modelo do APL. 
A Figura 3- mostra as mesmas cinco forças e as vantagens competitivas sob a perspectiva de um Arranjo de Produção Local.

\section{AMEAÇAS DE ENTRADA}

A entrada de novas empresas passa a ser positiva.

Quanto mais concorrentes se unirem, maior a força do APL.

A concorrência deixa de existir em níveis de compras,

logística, distribuição e vendas.

\section{O PODER DOS}

FORNECEDORES

Os Fornecedores não mais

negociam isoladamente com

cada empresa.

Informações sobre preços dos

fornecedores são

compartilhadas entre as

empresas.

As condições dos fornecedores

são as mesmas para todas as

empresas, que podem negociar

em grupo ou isoladamente,

mas sempre em prol do APL.

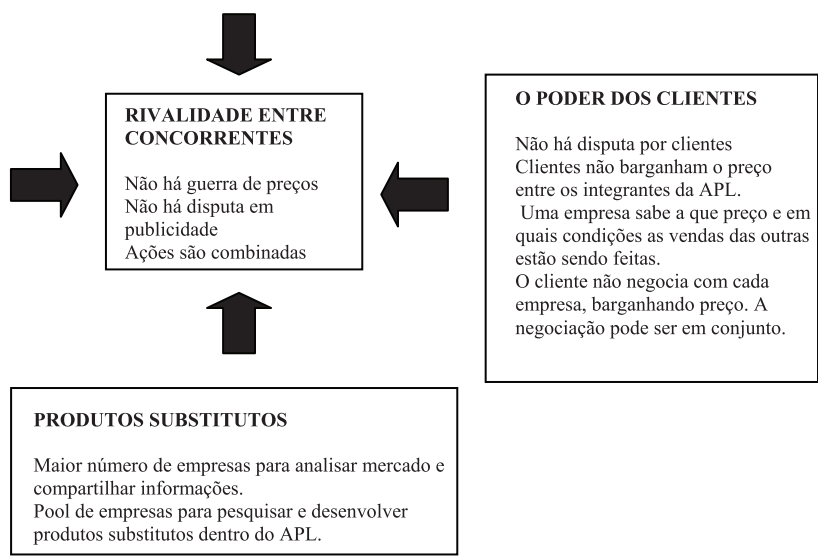

Figura 3: A Vantagem Competitiva de empresas organizadas em APLs sob a perspectiva das 5 forças de Porter.

\section{Conclusão}

O presente trabalho teve como objetivo verificar se as empresas associadas em Arranjos Produtivos Locais apresentam vantagens competitivas em relação às empresas, trabalhando isoladamente. Foram utilizados alguns modelos teóricos como "As cinco forças de Porter" e o modelo e tipologia de APLs de Mytelka e Farinelli.

A pesquisa permitiu observar que, em diversos aspectos da análise, empresas agindo isoladamente, comparadas àquelas inseridas em Arranjos Produtivos Locais, mostram os seus pontos fracos em muitos níveis e intensidades. A comparação entre as forças de Porter e a atuação das empresas organizadas em APL permitiu inferir que a Vantagem Competitiva de indústrias em APLS se forma por fatores relacionados principalmente a: 
a) Clientes;

b) Fornecedores;

c) Sistemas de logística;

d) Desenvolvimento de novos produtos;

e) Manutenção de margens e rentabilidade;

f) Facilidade de acesso a pesquisa e tecnologia;

g) Facilidade de acesso a novos mercados;

h) Proteção contra novos concorrentes; e

i) Ajuda de órgãos de fomento e desenvolvimento.

A pesquisa prescinde, no entanto, de dados quantitativos. O estudo trouxe, por um lado, resultados satisfatórios. Ficou clara a supremacia de indústrias pertencentes a Arranjos Produtivos Locais, sob a perspectiva das 5 forças de Porter, mas o resultado não foi conclusivo em relação à grandeza dessa vantagem.

Uma pesquisa mais aprofundada deverá ser efetuada para se verificar, quantitativamente, os aspectos relacionados, principalmente, com fornecedores, clientes e mercados em um APL, formalmente organizados no Brasil para oferecer embasamento ao presente artigo.

\section{Bussiness enterprise partnership in Brazil in local productivity arrangements (APL) as a factor of advantage competitif gain.}

\section{Abstract}

In recent years, several studies have been published about the importance of association or agglomeration of Local Productive Arrangements (LPA) companies as a development instrument, aiming productive capacity and competitive advantage. Several studies have been published recently confirming the economic viability of these arrangements. Researches have shown that though cooperation competitive differentials are created for the industries embedded in the group. 
The agglomerations built as mentioned are usually called APLs by many authors. Several other names however are being used by scholars to define the arrangements, such as: Local Innovation Systems, Local Production Systems, Local Production Arrangements and Cluster. The Brazilian government officially decided to name this kind of agglomeration "Local Productive Arrangements" (APLs), as we are going to do from now on in this study.

The main purpose of this text is to show that the companies belonging to APLs have competitive advantage factors not available when isolated from them, using the Porter, Mytelka or Farinelli models.

Keywords: Local Productive Arrangement. Network as a Strategic Model. Clusters. Competitive Advantages. Local Production Systems.

\section{Referências}

BANCO NACIONAL DE DESENVOLVIMENTO ECONÔMICO E SOCIAL. Arranjos produtivos locais e desenvolvimento. Brasília: BNDES, 2004.

BRASIL. Ministério do Desenvolvimento da Indústria e do Comércio. Termo de referência para política nacional de apoio ao desenvolvimento de arranjos produtivos locais. Brasília: Ministério do Desenvolvimento da Indústria e do Comércio, 2004.

FERREIRA, Ademir; REIS, Ana C. F; PEREIRA, Maria I. Gestão empresarial: de Taylor aos nossos dias - Evolução e tendências da moderna administração de empresas . São Paulo: Cengage Learning, 2008.

GARCIA, G. M. A gestão da mudança nos arranjos produtivos locais. São Paulo: CPL, 2006.

LASTRES, H. M. M.; CASSIOLATO, J. E.; MACIEL, M. L. Pequena empresa: cooperação e desenvolvimento local. Rio de Janeiro: Relume Dumará, 2003. 
MAY, Gabriela O. ; LEMOS, Dannyela da C. Proposta de um produto para o mercado brasileiro de telefonia celular. In: ENGEP - INDUSTRIAL ENGENEERING AND OPERATIONS MANAGEMENT. São Paulo, 1998.

MYTELKA, L.; FARINELLI, F. Arranjos e sistemas produtivos locais e as novas políticas de desenvolvimento industrial e tecnológico. Artigo apresentado no Engep Industrial Engeneering and Operations Management, São Paulo, 2000.

PORTER, Michael. Vantagem competitiva. Rio de Janeiro: Campus, 1989.

ROXO, F. V. O modelo das cinco forças de Porter. Portal do Marketing, 16 de maio de 2007. Disponível em: <http: //www. portaldomarketing.com.br/Artigos/Modelo_das_Cinco_Forcas_de_Michael_Porter.htm> Acesso em: 02 de jun. de 2009.

SANTOS, Gustavo. A. G.; DINIZ, Eduardo J.; BARBOSA, Eduardo K. Aglomerações, arranjos produtivos locais e vantagens competitivas locacionais. Revista do BNDES, Rio de Janeiro, 2004.

SCHMITZ; NADVI, K. Clustering and industrialization: introduction. World Development, [S. 1.] v. 27, n. 9, pp. 1503-1514, 1999.

SUZIGAN, W et al. Sistemas locais de produção: mapeamento, tipologia e sugestões de políticas. In: XXXI ENCONTRO NACIONAL DE ECONOMIA, 31,Porto Seguro, 2003.

TAVARES, Mauro C. Gestão estratégica. São Paulo: Atlas, 2007. 


\section{Para publicar na revista Universitas Gestão e TI, entre no endereço eletrônico www.publicacoesacademicas.uniceub.br. Observe as normas de publicação, facilitando e agilizando o trabalho de edição.}

